Supporting Information

Direct Gradient Photolithography of Photodegradable Hydrogels with Patterned Stiffness Control with Sub-Micron Resolution

Sam C. P. Norris, Peter Tseng, and Andrea M. Kasko*

Macromer Synthesis:

Figure S1. Chemical structure of the PEG 4000 4-(3-(Acryloyloxymethyl)-2- nitrobenzyloxy)-4oxobutanoate photodegradable macromer (PDG-PEG 4 k-DA)<smiles>C=CC(=O)OCc1cccc(COC(=O)CCC(=O)OCCC(C)OCC[18O]C(=O)CCC(=O)OCc2cccc(COC(=O)C=C)c2[N+](=O)[O-])c1[N+](=O)[O-]</smiles> 


\section{Exposure Conditions:}

Table S1. Design Guidelines of the SF-100 as provided by the manufacturer.

\begin{tabular}{lcccc}
\hline & $\begin{array}{c}2 \times \\
\text { Reduction } \\
\text { Lens }\end{array}$ & $\begin{array}{c}4 \times \\
\text { Reduction } \\
\text { Lens }\end{array}$ & $\begin{array}{c}10 \times \\
\text { Reduction } \\
\text { Lens }\end{array}$ & $\begin{array}{c}20 \times \\
\text { Reduction } \\
\text { Lens }\end{array}$ \\
\hline $\begin{array}{l}\text { Maximum } \\
\text { Recommended }\end{array}$ & $\begin{array}{c}6 \times 6 \\
\text { inches }\end{array}$ & $\begin{array}{c}6 \times 6 \\
\text { inches }\end{array}$ & $\begin{array}{c}4 \times 4 \\
\text { inches }\end{array}$ & $\begin{array}{c}4 \times 4 \\
\text { inches }\end{array}$ \\
$\begin{array}{l}\text { Design Size } \\
\text { Approximate }\end{array}$ & $2.5 \mu \mathrm{m}$ & $1.25 \mu \mathrm{m}$ & $0.50 \mu \mathrm{m}$ & $0.25 \mu \mathrm{m}$ \\
$\begin{array}{l}\text { Pixel Size } \\
\text { Single }\end{array}$ & & & & \\
$\begin{array}{l}\text { Exposure } \\
\text { Window Area }\end{array}$ & $1.92 \mathrm{~mm}$ & $0.96 \mathrm{~mm}$ & $0.384 \mathrm{~mm}$ & $0.192 \mathrm{~mm}$ \\
\hline
\end{tabular}

For the hydrogels presented in this paper, certain exposure condition were used. For the $4 \times, 10 \times$, and 20× reduction lenses of the maskless lithography machine, exposure times of 720 seconds, 240 seconds, and 60 seconds were used, respectively, for each exposure window unless otherwise noted.

For the gradient hydrogels, the $20 \mathrm{wt} \%$ gels used the $10 \times$ reduction lens and a gradient size of $204 \times 147$ pixels with the 8-bit grayscale pixel intensities ranging from $0-255$. The $10 \mathrm{wt} \%$ gels used the $4 \times$ reduction lens and a gradient size of $101 \times 71$ pixels with the 8 -bit grayscale pixel intensities ranging from 50-255. The $10 \mathrm{wt} \%$ gels used for the cell studies used a variation of gradient sizes and patterns, but the 8-bit grayscale pixel intensities still ranged from 50-255. For the $10 \mathrm{wt} \%$ gels, the lower 8-bit pixel intensity of the gradient was raised to 50 since it was noticed that pixel intensity values below that were not substantially degrading the substrate. Since cells were being seeded on top of the gels, the value was raised. The lower 8-bit pixel intensity of the gradient for the $10 \mathrm{wt} \%$ gel was raised to match that of the cell studies.

For the cell study, the exposure pattern was composed of a total of 16 exposure windows $(4 \times 4)$ stitched together.

For the $39 \mathrm{wt} \%$ hydrogel used for the resolution test, the $20 \times$ reduction lens was used with an exposure time of 240 seconds. 


\section{Resolution Calculation:}

To calculate the resolution of this system, the $20 \times$ reduction lens with the $39 \mathrm{wt} \%$ gel was used. The DMT modulus from the atomic force microscope (AFM) was collected in scanning mode to find the minimum distances the modulus of the gel could be altered controllably. The DMT modulus image was first corrected by subtracting the mean of each scan line from its self to remove scan line artifacts. The modulus pixel values were then averaged in the vertical direction to get an average modulus value for each exposed line (Figure S2a). This averaged line is called the line spread function (LSF) of the hydrogels resolution. The LSF was then processed by two low pass filters (Figure S2b) - one to capture background changes in the modulus map, and the other to capture the variations of the modulus caused by the degraded lines. The lower frequency filtered data was then subtracted from the higher frequency filtered data and divided by the lower frequency filtered data (Figure S2c,d):

$$
\text { Filtered AFM Signal }=\frac{\text { Higher frequency data }- \text { Lower frequency data }}{\text { Lower frequency data }} \text {. }
$$

Figure S2c shows a series of dips and peaks corresponding to the degraded (lower modulus) and undegraded (higher modulus) regions. The resolution (Figure S2e) pattern is constructed such that there are lines of increasing size from left to right: 1 pixel on, 1 pixel off, 2 pixels on, 2 pixels off, 3 pixels on, 3 pixels off, and so on... until all 1024 pixels have been filled. These pixel-based line widths correspond to projected line widths of $0.25 \mu \mathrm{m}, 0.50 \mu \mathrm{m}, 0.75 \mu \mathrm{m} . .$. , respectively using the $20 \times$ lens. The distance from a dip to the next peak in Figure S2d gives the width of the degraded line. The dip to peak distances recorded in Figure S2d correspond to the pixel widths given in Figure S2e. 
Figure S2. Resolution test: a) AFM modulus image and mean modulus in the vertical direction. b) mean modulus (black), with low pass filter following substrate features (red) and general background (blue). c) AFM modulus image with calculated line spread function. d) Line spread function with corresponding degraded line widths. e) Pixel distance of input mask and corresponding projected size.

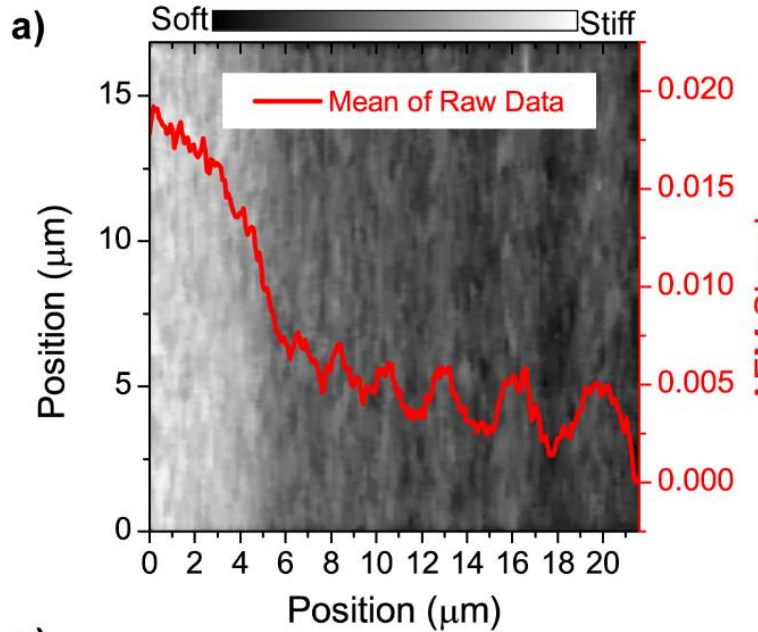

c)

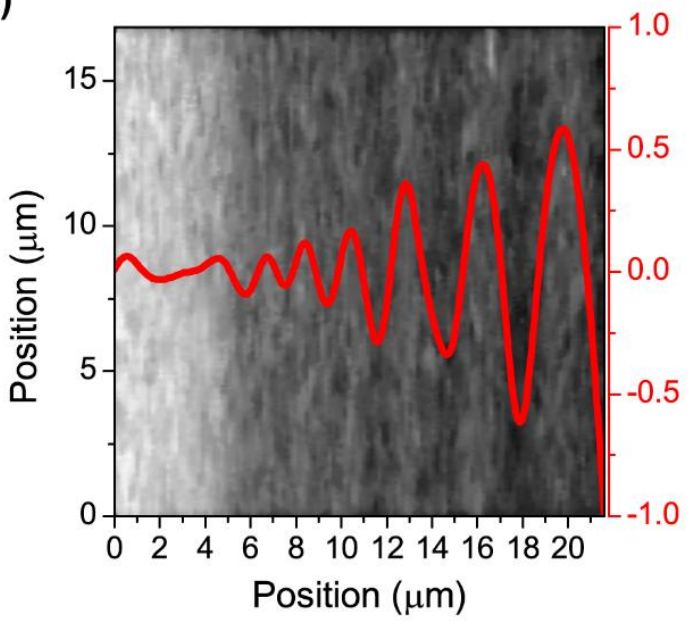

b)
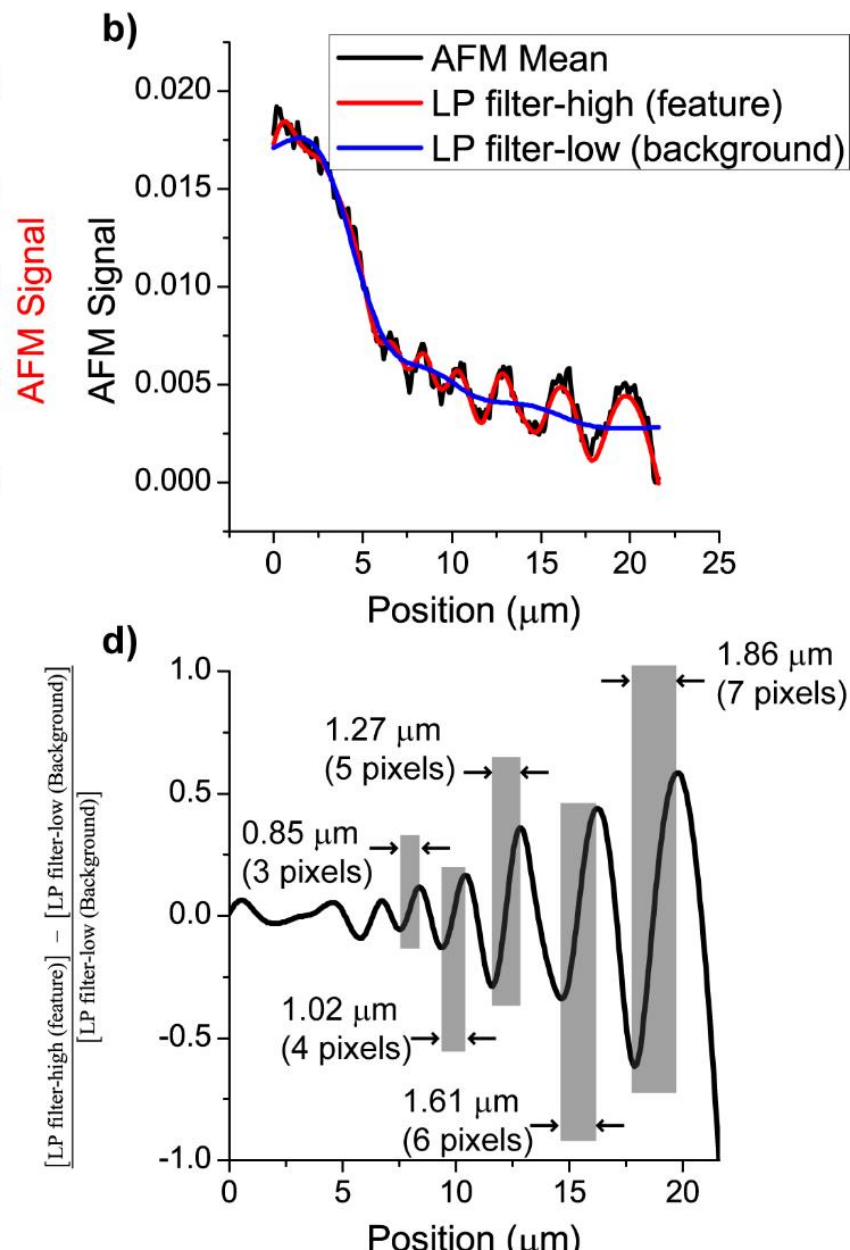

d)

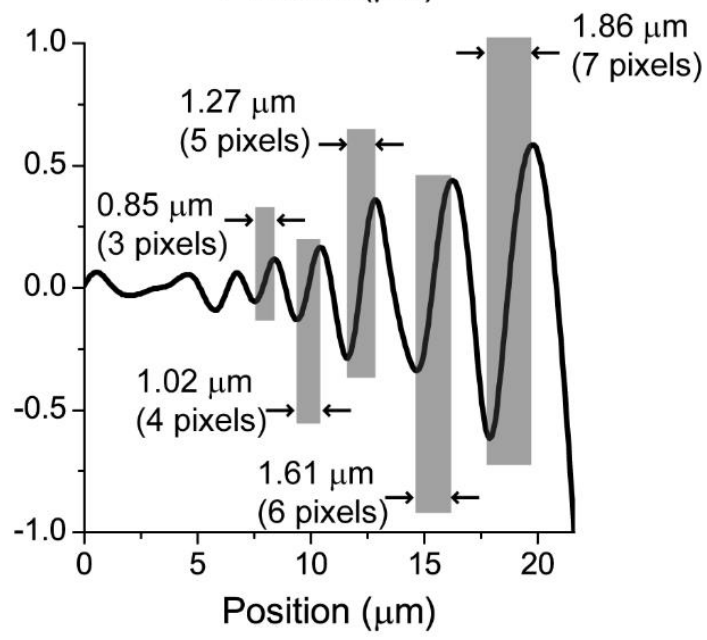

e) $\rightarrow \leftarrow$ pixel $(0.25 \mu \mathrm{m})$

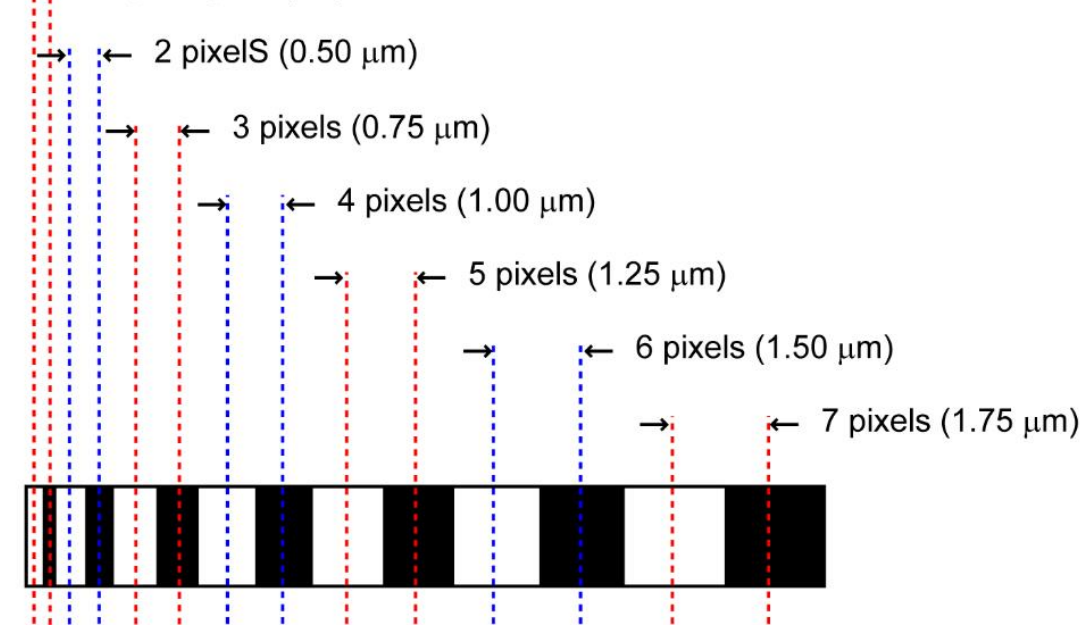




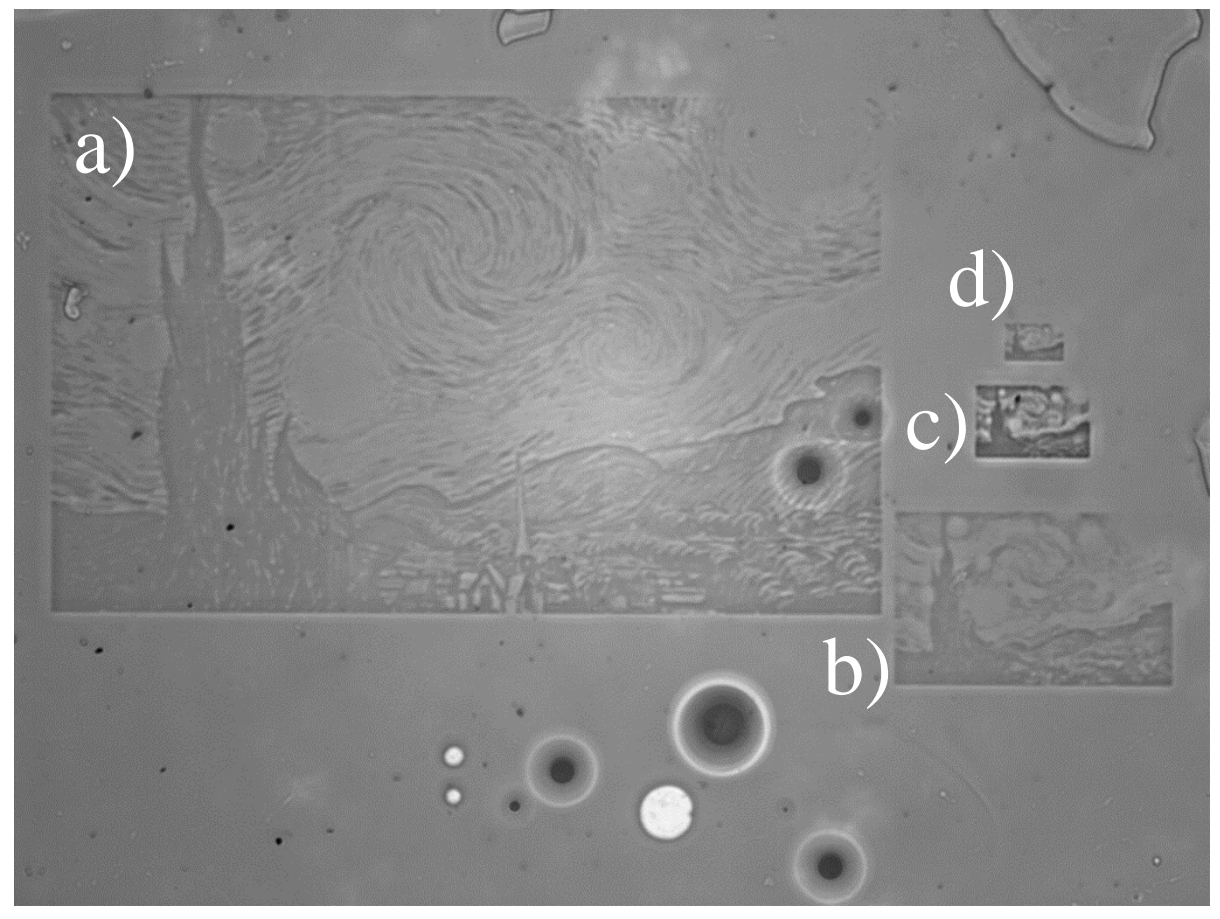

Figure S3. Variation of hydrogel lithograph length scales can be achieved using a) the $4 \times$ reduction lens with nine exposure windows stitched together $(3 \times 3)$, or using a single exposure window with the b) $4 \times$ reduction lens c) $10 \times$ reduction lens, and d) $20 \times$ reduction lens. The 20 $\mathrm{wt} \%$ gel was used for these images.

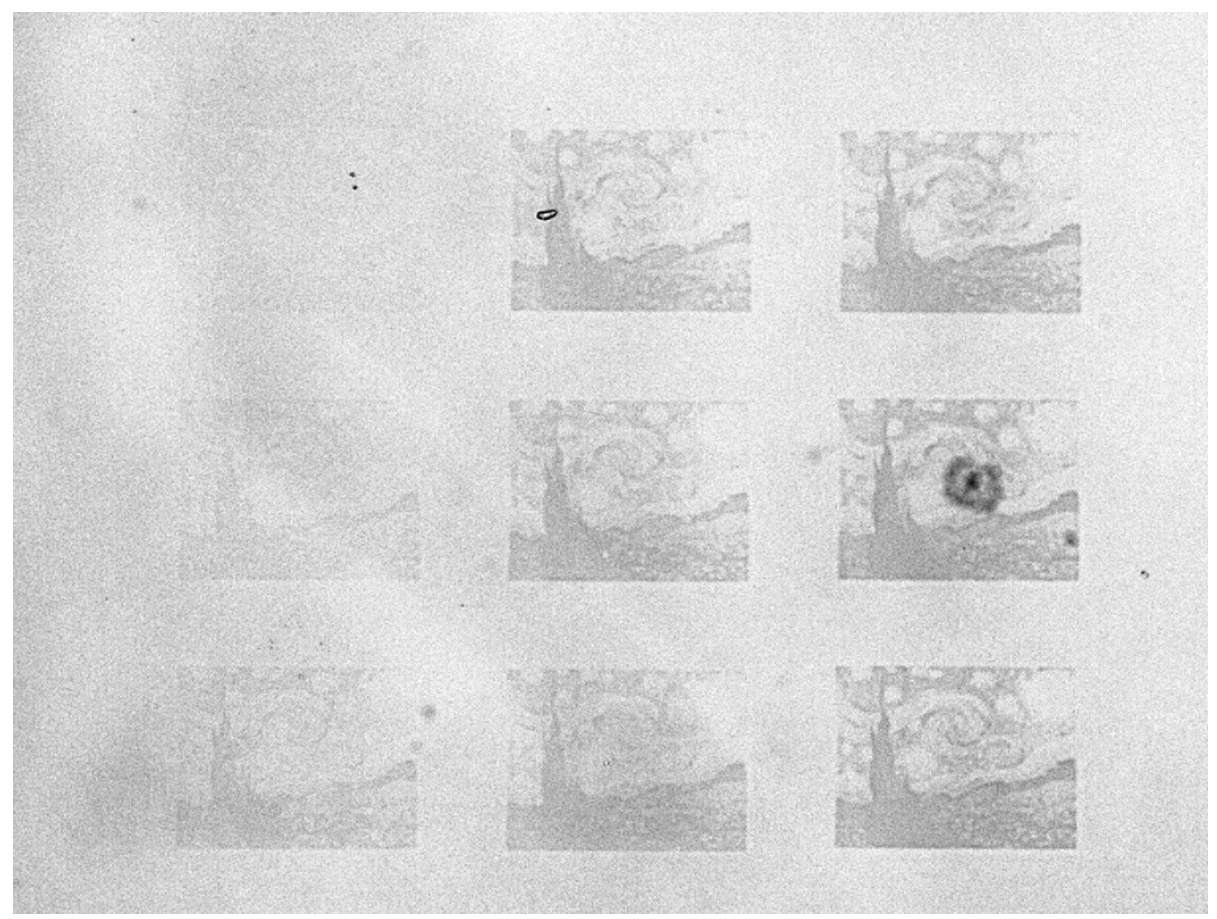


Figure S4. Variation of hydrogel lithograph degradation using the $10 \times$ reduction lens ranging from 30 to 270 seconds at 30 second intervals. This can be used to calibrate the exposure condition for a particular experimental setup. The $20 \mathrm{wt} \%$ gel was used for these images. 